\title{
The Misconception of Rural Development in South Africa: A Recipe for Socio-Economic Stagnation
}

\author{
Thanyani S Madzivhandila \\ Department of Development Planning \& Management, University of Limpopo, \\ South Africa, Private Bag X1106, Sovenga, 0727 \\ thanyani.madzivhandila@ul.ac.za
}

\section{Doi:10.5901/mjss.2014.v5n8p89}

\begin{abstract}
The conventional understanding of development as conditional improvement is no longer entirely tenable. That is, the current perceptive meaning of what developed and non-developed should constitute, has a geographical and material view. This has led to the distinction of rural and urban areas, where urban constitutes living in advanced socio-economic conditions, while rural, consequently refers to the extreme life characterised by poverty and survival competition for socio-economic opportunities. This conceptual paper argues that while it is generally accepted that agricultural activities characterise rural life in third world countries, in South Africa this has proved to be a misconception. Agricultural activities are found to be commercially oriented, whereas rural living is more leaning towards non-farm socio-economic activities. This misconstruction of rural development has thus lead to unsustainable rural socio-economic progress. The purpose of this paper is therefore to uncover the current understanding of rural development and its strategies, socio-economic conditions pertaining to rural areas and challenges facing implementation of rural development strategies in South Africa. The paper concludes that whereas urban living cannot be envisaged a blue print for developed rural areas, rural development should ample sustainable socio-economic choices, namely: employment opportunities, access to market activities and social welfare services for rural population, for reducing an excessive rural-urban dependency.
\end{abstract}

\section{Introduction}

For many decades now, the majority of countries around the globe have been battling with a fundamental challenge of ensuring that socio-economic conditions in rural areas are improved in a sustainable manner. That is, rural development initiatives and strategies have continuously failed to secure food, alleviate poverty, and create sustainable employment opportunities, health care and capacity building for the rural population (Ellis, \& Biggs 2001; Rizov \& Wiggins \& Proctor, 2001; Desai, \& Potter 2002). In policy terms, rural development has lacked a convincing narrative, offering little manageable and internationally agreed solutions to clear and well understood problems. Key issues to this has always been that many rural development policies still recognise agriculture and land as the sole engine for rural development. This approach ignores the fact that the diverse socio-economic conditions and challenges in these areas require more holistic interventions which include, amongst others, the need to embrace the potential of the non-farms rural activities and livelihoods (Cheshire, 2000). Traditionally, it can be argued that agriculture is an important sector in rural South Africa. However, nowadays other than large profitable commercial farmers, rural subsistence production units barely exist. So an optimal solution is to specialise and diversify into other activities than farming alone while contributing towards the diversity of the rural community. The solution to rural problems will require a huge investment by the government as rural areas in South Africa are still rattled by poor infrastructural development and institutional support mechanisms for meeting minimum or basic needs, lack of decent shelter, food insecurity, lack of water and poor sanitation.

This paper provides a wide account for the requirements of a multi-sectoral approach towards achieving sustainable rural development in South Africa. The paper commences by providing a rigorous background analysis of the current socio-economic conditions and strategies of rural development in rural areas. Secondly, the paper provides a discussion on the perceived misconception of rural development creating a slow paced rural development progress. Lastly, the paper provides a thorough discussion on pertinent issues to be considered to move towards new rural development approach that will provide for a successful and sustainable rural development initiative in South Africa and concludes by providing recommendations of measures required for facilitating a successful rural development strategy in South Africa. 


\section{Socio-Economic Conditions and Strategies of Rural Development in South Africa}

The concentration of poverty in rural areas has always been a stumbling block for development to take place smoothly and sustainably. This has been attributed to unequal resource distribution, unemployment, skills shortage, poor infrastructure and weak economic base in rural areas as a result of the legacy of apartheid. The multi-complexity of these rural features has created a far reaching impact on the formulation of thorough rural development strategies aiming at improving the standard of living of the poor, creating employment opportunities and capacity building among the unskilled able bodies in the rural areas (Murdoch, 2000; Rizov, 2005; Republic of South Africa (RSA) 2011). Ironically, rural areas are found to have abundance of land and other natural resources but poverty continue to affect its majority inhabitants severely i.e. the average incomes are lower in rural areas than the towns and cities and the proportions of people living below specified poverty lines are higher (Desai \& Potter 2002). The question to ask is, why are rural areas remaining poorer?, certainty not for lack of natural resources, but superior access of urban inhabitants to financial, physical, human and social capital, compared with rural counterparts is playing a role in this regard.

Current improved socio-economic trends requires more than just access to food and land for agriculture but diverse employment activities for income accumulation to afford better and sustainable access to education, clean water, proper sanitation and dwellings, amongst others. One can argue that the enabling factors of development are lacking to fast-track the elevation of rural dimensions of development process because of the legacy of previous stage of industrial development where distinction between urban and rural areas were forged in ways that conformed to the spatial order of this earlier development mode (Murdoch, 2000; Ashley \& Maxwell, 2001). Rural areas are still recognised and associated with spaces where human settlement only occupying a small patches of the landscape, with poor infrastructure development and unskilled people. A myriad of rural development strategies which include amongst others green revolution, regenerating agriculture and rural co-operatives are found to have focussed on only one dimension of rural development which is food security. It is commonly argued that food security is the first priority for rural population; however, the current trend of socio-economic needs require more than just access to food.

Rural development strategies such as green revolution in the late 60s were meant to create a rapid growth in the third world grain output associated with the introduction of a package of tropical agricultural inputs (Rigg, 2006). The strategy introduced breeding of improved varieties combined with expanded use of fertilizers, other chemical inputs and irrigation. The main target of this strategy was to develop rice and wheat yields. However, it expanded to develop other major food crops important to developing countries, including sorghum, millet, maize, cassava and beans. Tilman (1998) described the success of green revolution as immense, because agriculture has met the food needs of most of the world population even as the population doubled. However, he mentioned the negative effects as contamination of ground water, release of greenhouse gases, and loss of crop genetic diversity amongst others. The other rural development strategy which was highly recommended was the regeneration of agriculture. Its strategic importance relied on the forward and backward integration with the rest of the economy, the establishment and maintenance of food security and the economic welfare of rural areas (Meyer, Breitenbach, Fenyes \& Jooste, 2009). The main aim of regenerating agriculture for food security was to facilitate for local farmers to have access to natural, financial, human, physical and social resources to improve their practices. Regenerating agriculture was seen as crucial for sustainable agriculture development and improvement of productivity, increase production yields and tackle adverse poverty experienced in rural areas. However, the strategy did a little to improve food security of the poor in rural areas.

Last but not least, rural agricultural co-operative were seen as an effective carrier to undertake the responsibility for controlling the agri-food quality safety. Because local farmers could not afford the required technology, capital and human cost required for controlling of the agri-food safety, agricultural co-operatives were enabling factors for farmers to access required technology to undertake the responsibility of controlling the agri-food quality safety (Desai \& Potter, 2002; XiangyuGuo, 2010). Again, they did not only make the separated farmers united, implementing united management and co-operative operation, but they also sought to ensure uniform benefits among farmers and the organisation. In practice, many co-operatives have made large performance in sustaining quality safety of agriculture products, raising farmers income and promoting market competitive power, which are realised through standardised production, production classification, packaging brand sale and quality traceability (XiangyuGuo, 2010). At the end of it all, these rural development strategies are important pillars in the quest to maximise food security amid many challenges that they encountered; however, the fact that most of them focus solely on the achievement of food security than other element of rural development left them wanting. A successful rural development is the one which makes rural communities more attractive for living and for tourists by providing variety of services locally, developing new enterprises for employment, proving goods and services according to the local comparative advantage. 


\section{Misconception as a Challenge for Rural Development}

"For most scholars and development practitioners, the poor world is largely a rural world and, in terms of livelihoods, this rural world is an agricultural one where farming predominates and where land is the critical resource" (Rigg, 2006:1). It is agreeable that land is a fundamental livelihood asset and secure, safe, and affordable land is a necessary. However, it is not always sufficient condition for reducing poverty. The success of rural development initiatives and strategies lies upon the realisation of multi-sectoral factors pertaining rural area settings. It is argued that, whereas rural areas are changing in size, structure, needs; capability of its population and patterns of economic activity, rural development policies and strategies have yet to catch up with these changes. The current trends and discontinuities in the character and complexities of these changes have generated problems and confusion among policy makers (Ellis, \& Biggs 2001; Rizov \& Wiggins \& Proctor, 2001). Most rural development strategies formulated have continuously been guided by a common misconception that conflates the 'farm' and the 'rural' space. Thus, the initiatives emanating from these strategies have been obsessed with facilitating land redistribution for agriculture purpose as the main solution to rural community's problems. Lives and livelihoods in the rural South Africa are becoming increasingly divorced from farming and, therefore, from the land oriented dependency. Again, there are many flaws in the understanding of the term 'rural' among rural development scholars, thus, contributing to the misrepresentation of some of its characteristics in the rural development strategies. In fact Ashley \& Maxwell (2001) emphasised that the term 'rural' is ambiguous and it does not have an exact definition. Wiggin \& Proctors (2001) also agreed with this, however, adding that even without a clear definition some areas are clearly recognisable as rural. Such areas are seen to constitute the space where human settlement and infrastructure occupy only small patches of the landscape, most of which is dominated by fields and pastures, woods and forest, water, mountains and desert.

The lack of common understanding of the concept rural means that the misconceptions about sets of rural development ideas guiding strategy formulation across different disciplines, centres of learning, influential think-tanks will also be uneven. The more dominant understanding of rural development is that of facilitation of agricultural activities as the main pillar for food security. Moreover, Ellis \& Biggs (2001) argued that the one major body of thought has dominated the landscape of rural development thinking is agricultural growth based on small-farm efficiency paradigm. However, according to Ashley \& Maxwell (2001), there is more to rural development than agricultural production. Agriculture has and is still failing to meet the requirement as criteria for rural development as it is dominated by private sector activities than community food security oriented ones. Many agricultural plots in rural areas are privately owned and their products solely imported to areas with economic potential for profit purpose. Those households who relied on subsistence farming are also now discouraged because of rapid crop failure attributed to current extreme climatic conditions. In light of this, it is evident that the tendency to equate the rural economy with only agriculture is questionable. The rural development strategy that will have an impact to rural community is the one which acknowledge the need to increase diversification of rural economy. Patterns and associations of wealth and poverty have become more diffuse and diverse as non-farm opportunities have expanded and heightened levels of mobility have led to the delocalisation of livelihoods (Rigg, 2006). Currently, evidence shows that the rural poor depend more on non-farm, often non-rural sources of income to sustain their livelihoods. So, rural development has to be about all the various assets rural people access, and about the structures and process which mandate how those assets are transformed into income and other desired outcomes.

\section{Moving towards Equitable Rural Development Approach}

Notwithstanding the fact that agriculture and farm activities play a big role in securing food for the poor residence in rural areas and that agriculture productivity can be an important determinant of poverty alleviation, and with an increase in yields there is a potential to lift a large number of individuals out of poverty (Ashley \& Maxwell 2001; Ellis, \& Biggs 2001; Rizov \& Wiggins \& Proctor, 2001; Desai, \& Potter 2002). In recent years, agriculture has been open to national and international trade, making its product expensive to be afforded by the poor in rural areas, thus requiring alternative strategies to develop local economies. Ashley \& Maxwell (2001) argue that, rural areas are changing and their realities are not what they used to be particularly with respect to demography, diversity and strengthening links to national and global economy. In order for rural development strategies to be affective they should adapt to this changes with a view to allow for the integration of multi-sectoral activity demonstrating the importance of state intervention, calling for new partnerships with civil society, and emphasising the importance of a political dimensions. Ashley \& Maxwell (2001) identified five principles for a successful rural development strategy as follows; the strategy should recognise the great diversity of rural situations; favour livelihoods strengthening diversification options for multi-occupational and multilocational households; recognise the importance of investment in infrastructure; and, human capital. Concurrently, such a 
rural development strategy will have to focus on issues of rural community development, incorporating strategies for the sustainability of the economy, social and cultural sphere of rural life, thus, emphasising participatory process that will empower rural dwellers to take control of their own priorities for change (Wiggins \& Proctor, 2001). This spatial approach implies an attempt to co-ordinate a range of activities i.e. non-farm activities and livelihoods located within an area so that the capacity of local actors to gain access to markets and to other economic opportunities is heightened.

Livelihoods diversification is regarded as a core issue, and of great current interest both to developing country governments and to donors. Hence, achieving optimum diversity at community level is a key in solving the rural development problems. For a rural development strategy to work, village economies have to be diverse-producing not only food and fibre from agriculture, but also clothing, housing, tools implements, furniture and energy amongst others. That is, there should be a strong emphasis on strengthening alternative rural non-farm economy. Recent survey suggest that non-farm sources account for $40-45 \%$ of average rural households income in sub-Saharan Africa and Latin America, and $30-40 \%$ in South Asia with the majority coming from local rural sources rather than urban migration (Ellis, \& Biggs 2001). Rural tourism provides examples of the potential of the rural non-farm economy and of how to increase benefits to the poor. Ashley \& Maxwell (2001) argue that, currently it is difficult to imagine an effective rural poverty reduction strategy for Africa that does not seem to harness the potential of the non-farm sectors. The thought ingredients for a success rural development strategy which incorporates non-farm activities include; identify options for increasing access to social-business networks; develop small towns; support producer associations for marketing and sourcing; removing regulatory or bureaucratic burden on small and medium enterprise; reforming extension into business advisory services (Ashley \& Maxwell, 2001). Ellis \& Biggs (2001) argue that, intensive interventions will be needed which enable the poor to overcome entry barriers and participate in more productive aspects of the rural non-farm economy. Training and credit are obvious interventions, and other state interventions which can smooth transition with long-term comparative advantage. The interventions to promote rural non-farm activities can be expensive option involving a long-term investment perspective and strong ideals of regionally decentralised development and more spatially equitable outcome. Hence its success depend on a maximum investment, state policy, regulation and co-ordination, for example, providing infrastructure, legislation to secure tenure and using planning controls to encourage private operators.

\section{Conclusion}

The paper has demonstrated that the understanding of the concept rural development is convoluted by the fact that it is enmeshed in misconception regarding its proper meaning and application. To this end, it is evident that the quest for a new rural development approach will be realised only if agriculture takes its place along with a host of other actual and potential rural and non-rural activities that are important to the construction of viable rural livelihoods, without undue preference being given to farming as the unique solution to rural poverty and development. It is in this sense that the cross-sectoral and multi-occupational diversity of rural livelihoods may need to become the cornerstone of rural development policies and strategies if efforts to reduce rural poverty are to be effective in the future. Rural development should entails a strengthening of local productive capabilities in ways that benefit the rural economy as a whole solidification of rural economies wherein new industries and associated technologies, skills and patterns of working would be imparted into rural areas in order to overcome problems of marginalisation and backwardness. This approach will also allow for the integration of rural areas into the national and international economies. However, State support is a foremost prerequisite for this process to take shape. The continuing problems faced by farmers and others involved in the agrofood sector highlight the extent to which agriculture is diminishing part of both food systems and the rural economy. Rural development strategies should focus upon the non-agriculture sphere as the growth in employment is most marked in the manufacturing and services. Rural development should look beyond food security but focus on wider concern such as health, education, participation and social protection.

\section{Reference}

Ashley, C. \& Maxwell, S. 2001 Rethinking rural development. Development Policy Review, 19:395-425.

Cheshire, L.H. 2000 Contemporary strategies for rural community development in Australia: a governmentality perspective. Journal of Rural Studies, 16:203-215.

Desai, V. \& Potter, R.B. (eds.) 2002 The Companion to Development Studies. London: Hodder Arnold.

Ellis, F. \& Biggs, S. 2001 Evolving themes in rural development 1950s-2000s. Development Policy Review, 19(4):437-448.

Meyer, N.G., Breitenbach, M.C., Fenyes, T.I. \& Jooste, A. 2009 The Economic Rationale for Agricultural Regeneration and Rural Infrastructure Investment in South Africa. Pretoria: University of Pretoria.

Murdoch, J. 2000 Networks-a new paradigm of rural development? Journal of Rural Studies, 16:407-419. 
Republic of South Africa (RSA) 2011 Rural Development and Land Reform General Amendment Act. Pretoria: Government Printers. Rigg, J. 2006 Land, farming, livelihoods, and poverty: rethinking the links in the rural south. World Development. 34(1) 180-202.

Rizov, M. 2005 Rural development under the European CAP: the role of diversity. Social Science Journal, 42:621-628.

Tilman, D. 1998 The greening of the green revolution. Nature, 396:211-112.

Wiggins, S. \& Proctor, S. 2001 How special are rural areas? The economic implications of location for rural development. Development Policy Review, 19(4):427-436.

XiangyuGuo, M. 2010 Study on functions of the agricultural cooperatives in food safety. Agriculture and Agricultural Science Procedia. 1:477-482. 